\title{
Aerodynamic Design and Experimental Investigation of the Sailplane Wing Tip Devices
}

\author{
P. Anderle, L. Smrček, F. N. Coton
}

This paper describes an experimental set-up for the investigation of wing tip devices developed as part of a study into the velocity and vorticity distributions in the flow field behind winglets, using hot-wire anemometry. In this study, effort was focused on gaining a greater understanding of what happens in the region where the winglet joins the wing. The measurements were performed in the Handley-Page wind tunnel of the Department of Aerospace Engineering at the University of Glasgow. In order to carry out measurements with the hot-wire anemometry system, a new traverse mechanism was designed and manufactured. This traverse mechanism was integrated with the other test instrumentation to create a complete measurement chain. The complete system allows fully automated hot wire measurements to be made over a defined area using programmable test parameters.

Keywords: winglet, hot-wire anemometry, traverse mechanism, vorticity.

\section{Notation}

$\omega_{\mathrm{x}} \quad$ vorticity component in $\mathrm{YZ}$ plane

b ving span

$\mathrm{V}_{\mathrm{X}}, \mathrm{V}_{\mathrm{Y}} \quad$ velocity components

$\mathrm{U}_{\infty} \quad$ free stream velocity

$\mathrm{Z} \quad$ downstream distance

\section{Introduction}

In the late 1960s, designers began experimenting with wing-tip geometries using 'small' vertical extensions to reduce the formation of tip vortices. The winglet concept actually dates back to 1897, when Frederick Lanchester took out a patent on the idea, incorporating it into some of his wing theories [1]. His wing had two 'capping planes' at the end of it, which became known in the 1920 s as 'end plates', when Prandtl extended his basic lifting line concept [2].

The real break-through with winglets was made by Whitcomb. In 1976, Richard Whitcomb, a NASA aerodynamicist, published a paper that compared a wing with a winglet and the same wing with a simple extension to increase its span [3] Whitcomb showed that winglets reduced drag by about 20 percent and increased the wing lift-drag ratio by approximately 9 percent. Induced drag represents $30-40$ percent of the total drag of a transport plane in cruise condition, so the induced drag reduction has a significant effect on fuel consumption. Whitcomb began a focused investigation into winglet aerodynamics and tested several designs in the wind tunnels at the NASA Langley Research Center. The first industrial application of the winglet concept was in general aviation business jets. For instance, it is claimed that a winglet on a Boeing-747 could significantly reduce fuel burn on long-range flights. Research into the effect of winglets on first generation jet transport wings showed that they can produce reasonable drag reduction in high lift conditions [4].

Winglets are now being incorporated into most new commercial and military transport jets. Since the 1980 s, the most modern high performance sailplanes also have small vertical wing tip extensions.

The first sailplanes to have winglets were the ASW-20FP, GEMINI and NIMBUS 3. Sets of Whitcomb style winglets were fitted to these wings in the late 1980s. Flight tests carried out on these aircraft demonstrated the effect of winglets on high aspect ratio wings [5].

\section{How do winglets work}

The primary effect of the winglet is to control the cross flow in the tip region of the wing in such a way as to reduce induced drag by displacing the vortices outward. The air flowing over the winglet, due to the presence of the tip vortex, strikes the winglet at an angle of attack. The winglet, like any wing, produces lift which, in this case, has a component in the forward direction. Thus, the winglet produces thrust (Fig. 1). This thrust component alters the cross flow at the wing tip
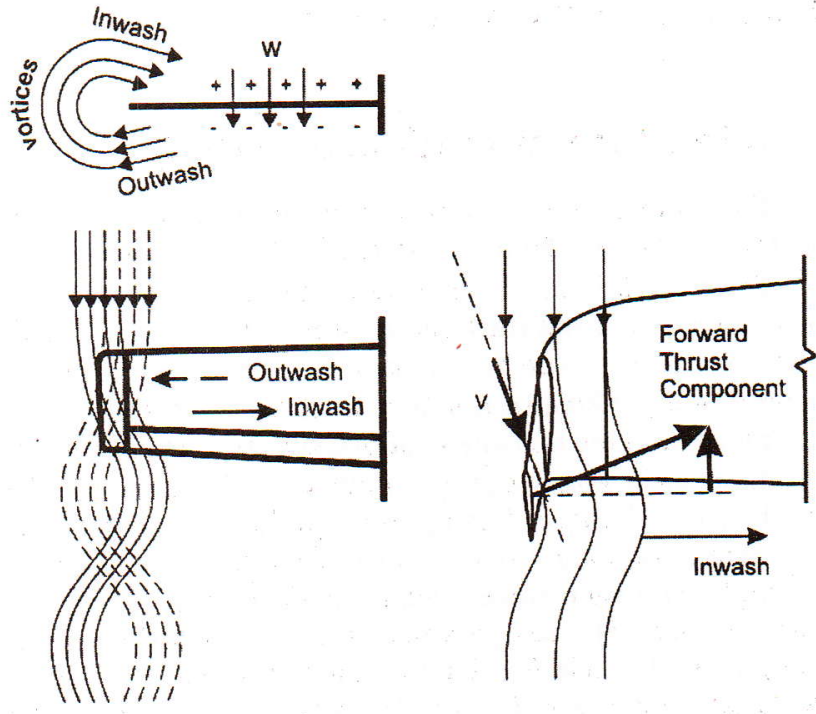

Fig. 1: Forward thrust component development 
and recovers some of the performance that would be lost through the additional drag caused by the increase in wetted area.

\section{Winglets for sailplanes}

Theory and experience have shown that the most efficient sailplane wing is one that is very long and slender. Having a high aspect ratio wing is one way of cutting wing-tip losses. In essence, the longer wing has the same tip losses but those energy losses will affect a lesser proportion of the total wing. In other words, the lift is distributed over the longer wingspan and the trailing vorticity is spread out, dissipating less energy.

From a construction point of view, a long wing is prone to flex and has to be strengthened; this adds weight. The winglet provides the effect of an increased aspect ratio without extending the wing-span and so does not increase the wing root bending as much as an actual span extension would. The moment arm of the lift from a span extension is approximately one-half of the wing semi-span, whereas the moment arm of the winglet lift is roughly only one-half of the vertical winglet span. This small increase does not overload the wing or significantly alter the standard operating limitations. The addition of winglets on sailplane wings also improves the maximum lift/drag coefficient for some $15 \mathrm{~m}$ span-limited FAI sailplane classes [6].

The induced drag coefficient is proportional to the square of the lift coefficient hence the reduction in drag also improves climbing capability [7], [8]. This improvement can be used when sailplanes circle in thermal bubbles, the main source of power to stay aloft [9]. Achieving a maximum cross country speed during sailplane competitions is another important consideration. Hence, the design of the winglets must involve the compromise of maximizing the low speed improvement without sacrificing high-speed performance [10].

The winglet added to an ASW-19 clearly showed that for some speeds the friction drag could exceed the induced drag reduction provided by winglets [11]. A correctly designed winglet can, however, be reasonably effective as illustrated in a study using the ASW-20 sailplane [12].

\section{Wind tunnel models of winglets}

The wind tunnel models used in the experiments were real wing tips taken from the wind of a $304 \mathrm{CZ}$ sailplane.

The models were mounted vertically on a base plate that was secured to a rail track mechanism. This mechanism allowed the model to be moved backwards and forwards in the wind tunnel working section to change the distance between the model and the hot-wire measurement plane. In addition, the base plate was designed to allow the incidence of the model to be changed. During the experimental programme four kinds of wing tip were investigated; a wing without a winglet and then three $304 \mathrm{CZ}$ sailplane wing tips of different design. The key parameters that defined the winglet designs are shown in Fig. 2, and are the winglet airfoil, sweepback, cant angle, twist distribution and the ratio of the winglet root chord to the winglet tip chord (taper).

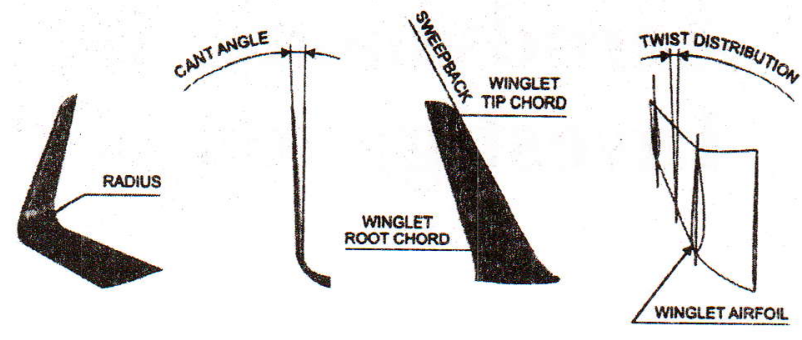

Fig. 2: Key Design parameters of winglets

\section{Wind tunnel}

The Handley Page wind tunnel is an atmospheric low-speed wind tunnel with a closed return circuit equipped with a rectangular testing-section of dimensions $2.15 \mathrm{~m}$ by $1.6 \mathrm{~m}$ and length $3.38 \mathrm{~m}$ (Fig. 3). The corners have $650 \mathrm{~mm}$ fillets that house lamps to provide lighting. Visual access to the working section is provided by 0,84 square metres of plate glass and acrylic windows that permit the model to be viewed from many angles. Several venting slots in the tunnel walls at the test section exit maintain near atmospheric static pressure. The nozzle placed in front of the testing section has a contraction ratio of $1: 4$. The power supply is an electric motor that drives a fan $2.3 \mathrm{~m}$ in diameter to provide the airflow in the wind tunnel. The tunnel can reach speeds up to $60 \mathrm{~m} / \mathrm{s}$.
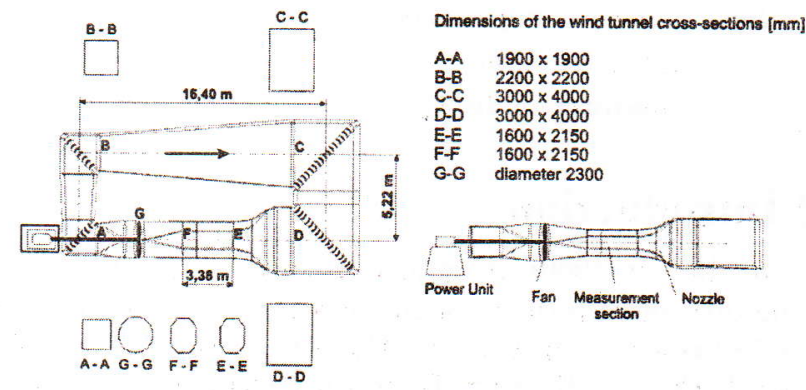

Fig. 3: Handley Page wind Tunnel, University of Glasgow

\section{Measurement procedure}

The measurement chain consists of an $\mathrm{x}$-wire sensor, a TSI IFA 300 constant temperature anemometry system, a personal computer, an SMOCI transmitter and a traversing mechanism, as shown in Fig. 4. This figure also shows the model mounting arrangement described previously. The $\mathrm{X}$-wire sensor is connected to two channels of the IFA 300 by coaxial cables. The IFA 300 hardware converts the acquired signals from the sensors and transmits them to the controlling computer via a $\mathrm{BNC}$ adapter block and data acquisition card. The IFA 300 software installed on the computer then processes the recorded data. Once the data has been recorded for an entire $\mathrm{X}$ traverse, a master program, written in LABView, sends a new instruction to the SMOCI unit. The SMOCI converts the instruction into the signal needed by the stepper motors to move the traverse to its next $\mathrm{Y}$ position. When the traverse mechanism reaches this new position, another signal is sent to it and it begins its X traverse. The $\mathrm{x}$-wire sensor continually samples data during this traverse and sends the signal to the computer. This process continues until measurements have been made over the entire measurement grid. 


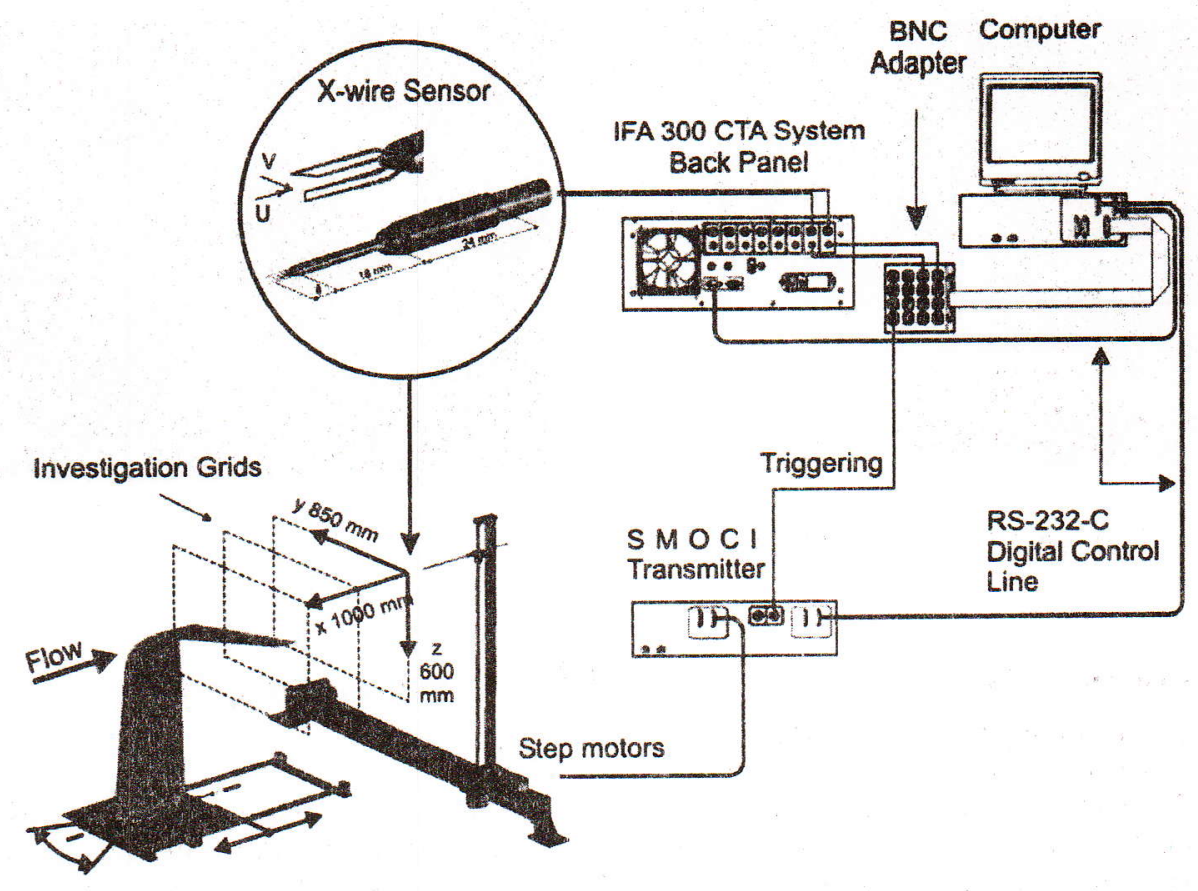

Fig. 4: Wind tunnel testing configuration

\section{Traverse mechanism}

The computer controlled traverse mechanism for probe positioning and data acquisition was specifically designed and manufactured for the present project. The traverse is a motorized two-component mechanism that can move the probe to any point within a $850 \mathrm{~mm} \times 930 \mathrm{~mm}$ grid. In the present series of tests the traverse was mounted behind the test models such that measurements could be made in planes perpendicular to the onset flow. The location of the measurement plane with respect to the test model could be varied using the model mounting tracks described previously. The way in which the traverse is assembled is shown in Fig. 5 below, and Fig. 6 . shows the assembled traverse in the wind tunnel together with a winglet model.

The horizontal motion is provided by a large, off-the-shelf linear slide driven by a stepper motor. Vertical movement is provided by a purpose-built traverse mechanism based on a precision ball screw, which is positioned in front of a linear slide mounted on an aluminium box-section support. The carriage of the ball screw is connected to the carriage of the linear slide and so, when the ball screw is driven by a stepper motor, the carriage moves up and down. The incremental resolution of the linear motion is $0.03 \mathrm{~mm}$.

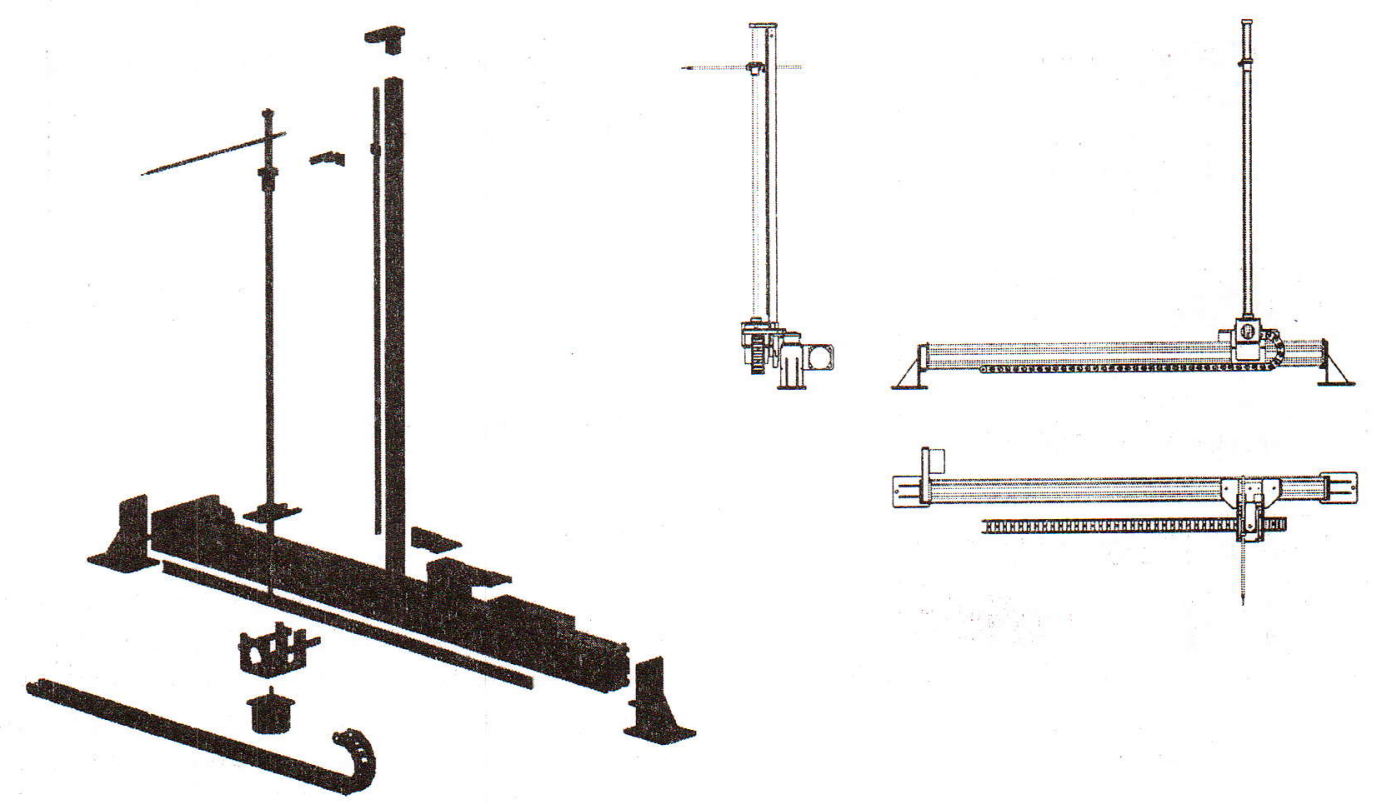

Fig. 5: Traverse mechanism 


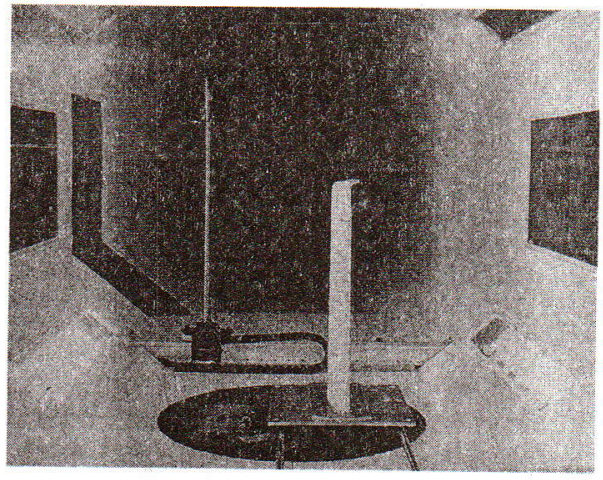

Fig. 6: Winglet models (1:1) placed in the Handley Page wind tunnel

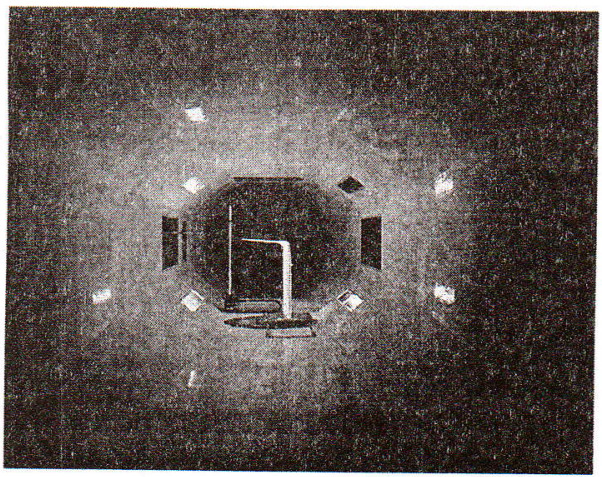

\section{Hot wire anemometry}

Measurements of the magnitude and associated direction of the time-dependent velocities behind the winglet models were obtained using a DANTEC 55P61 cross-wire probe connected to a TSI IFA-300 three-channel constant temperature anemometer system. The sensor wires on the probe are $5 \mathrm{~mm}$ diameter platinum plated tungsten wires with a length/diameter ratio of 250 , which form a measuring volume of approximately $0.8 \mathrm{~mm}$ in diameter and $0.5 \mathrm{~mm}$ in height. The wires are oriented perpendicular to each other, corresponding to 45 degrees from the free stream direction, which gives the best angular resolution. An additional temperature probe was used to correct the anemometer output voltages for any variation in ambient flow temperature. For probe calibration, an open jet vertical wind tunnel with a maximum operating velocity of $43 \mathrm{~m} / \mathrm{s}$ was used. A support allowed the sensors of the X-wire probe to be rotated by $30 \mathrm{degs}$ in the plane of the sensors. Variation of the flow velocity and yaw angle then enabled the coefficients of the effective velocity method to be determined. Fig. 7 shows how the hot-wire anemometry system was integrated into the overall measurement system.

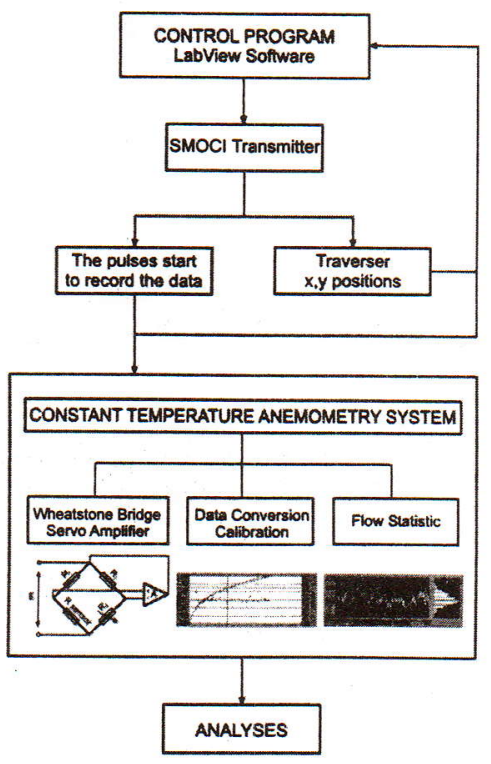

Fig. 7: Flow chart of data acquisition

\section{Investigation grid}

\section{X-travel:}

One step of the stepper motor provides $0.03125 \mathrm{~mm}$ of linear motion, and the time required for each step is $0.2980 \mathrm{sec}$. The size of the investigation grid in the $\mathrm{x}$-direction was $850 \mathrm{~mm}$ (Fig. 8) or 27200 steps of the stepper motor. The time required to traverse this distance was, therefore, $8.1055 \mathrm{sec}$.

At a sampling rate of $2000 \mathrm{~Hz}$, the sampling time of 8.1055 seconds gives a total of 16211 investigation points per line. To allow for turbulence in the flow, the data is averaged in blocks of 48 measurement points corresponding to approximately $2.5 \mathrm{~mm}$ of motion. Thus, 339 averaged data values are collected during each $\mathrm{X}$ traverse.

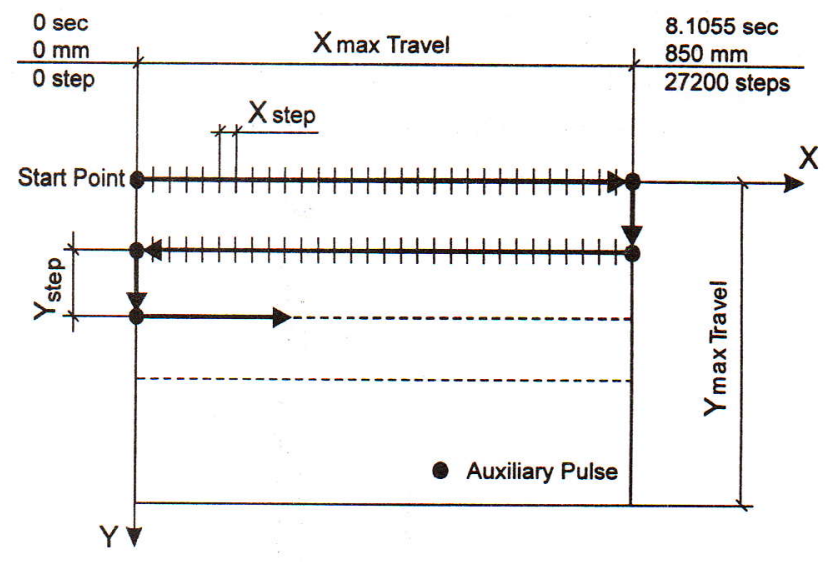

Fig. 8: Investigation grid

\section{Y-travel:}

The length of the investigation grid in the Y-direction was set at $600 \mathrm{~mm}$. This length was divided into steps of $5 \mathrm{~mm}$, giving a total of 121 measurement points in the $\mathrm{Y}$ direction.

The total time taken to traverse the entire $850 \mathrm{~mm} \times 600 \mathrm{~mm}$ grid was just over 20 minutes, and a total of 41019 measurements were obtained for each grid. The scheme of this process is presented in Fig. 8. 


\section{Experimental results}

The flow field behind the wing tip models was measured in three planes $(\mathrm{Z} / \mathrm{b}=0.2, \mathrm{Z} / \mathrm{b}=1, \mathrm{Z} / \mathrm{b}=2)$ for angles of attack $\alpha=(-3,0,3,6,9)$ degrees. For all tests the free stream velocity $\mathrm{U}_{\infty}$ was set at $33 \mathrm{~m} / \mathrm{s}(118.8 \mathrm{~km} / \mathrm{h})$ which corresponded to a Reynolds number of $\operatorname{Re}=0.8 \times 10^{6}$ based on the mean chord of the main wing. Data analysis and graphical presentation were carried out using Tecplot software in the form of vector plots of velocity distribution and contour line plots of the vorticity component $\omega_{\mathrm{x}}$ defined in equation 1 and Fig. 9 .

Figs. 10-13 present example measured data for four wing tip configurations in the plane $\mathrm{Z} / \mathrm{b}=1$ when the wing was at angle of attack $\alpha=3$ degrees and the free stream velocity was $U_{\infty}=33 \mathrm{~m} / \mathrm{s}$. These figures illustrate the effectiveness of the system in capturing the differences in the flow structures behind the different winglet configurations. For example, wing tip A (Fig. 10), which is basically a standard wing tip with a small vertical extension that projects downwards from the lower surface of the wing, produces an almost classical tip vortex structure where the vorticity is concentrated in a single structure that rolls up slightly inboard of the wing tip. Also visible in this figure is the vorticity in the wake of the main wing. Fig. 11, on the other hand, shows the velocity and vorticity distributions behind a much larger winglet extension. In this case, there are two clear vortex structures; one at the winglet/wing junction and the other at the tip of the winglet. The effect of sweeping this type of winglet back can be observed in Fig. 12, where measurements on a similar winglet with higher sweepback are presented. In this figure, the vorticity associated with the winglet/wing junction does not appear as a single well defined vortex but rather as a more spread-out region of vorticity. The winglet tip vortex is also less distinct, but it should be remembered that the tip of the winglet will be closer to the measurement plane in this case and so the roll-up may not be as complete. Finally, the effect of a small upward swept winglet is shown in Fig. 13. In this case, the vorticity is well distributed and follows the curvature of the winglet. It should be noted that these cases are presented merely as an example of the capability of the measuring system. The evolution of the vortex structures downstream of these wing tips is very complex and cannot be inferred from observation of the behaviour in a single measurement section.

$$
w_{x}=\frac{\partial V y}{\partial x}-\frac{\partial V x}{\partial y}
$$

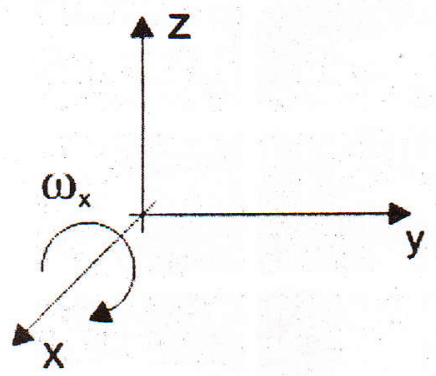

Fig. 9: Vorticity $\omega_{\mathrm{x}}$ component
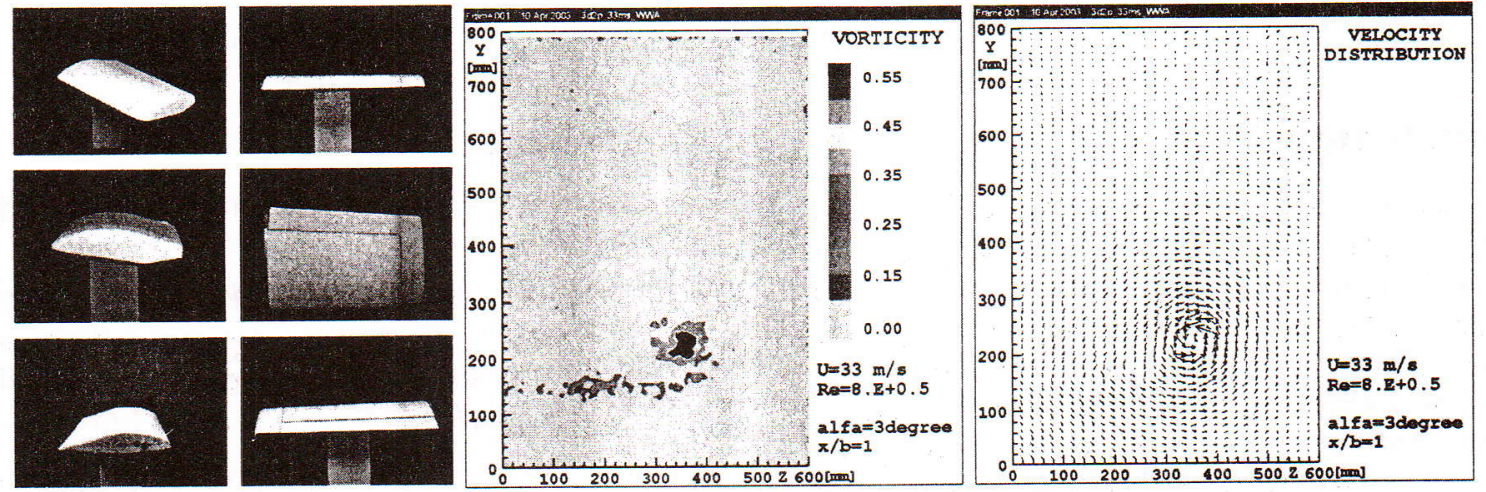

Fig. 10: Wing tip model A
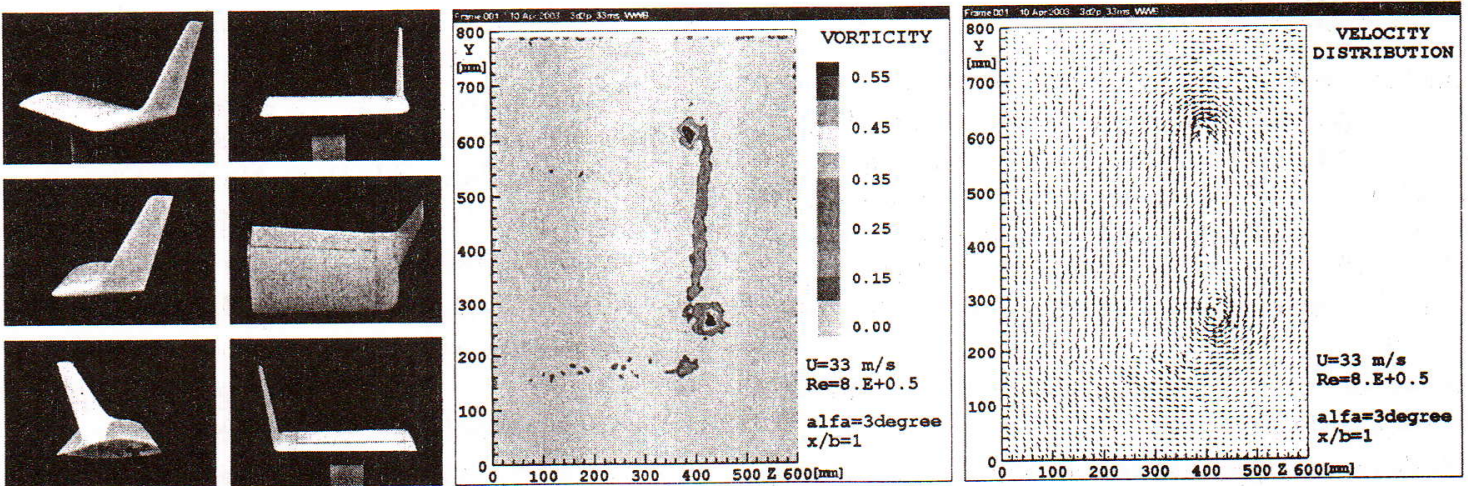

Fig. 11: Wing tip model B 

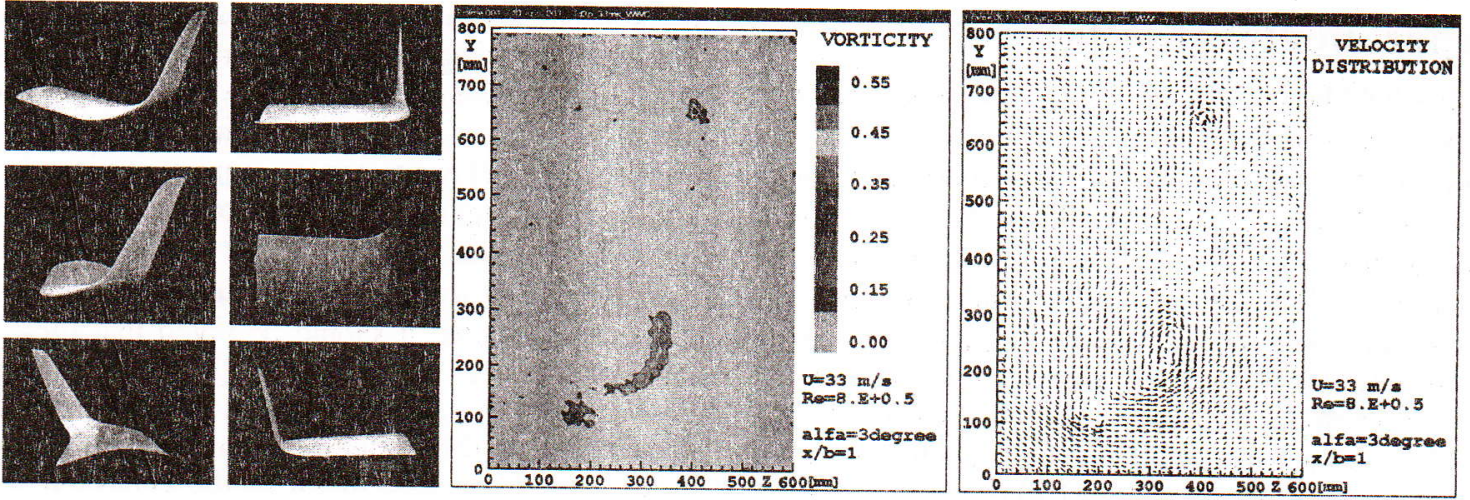

Fig. 12: Wing tip model C
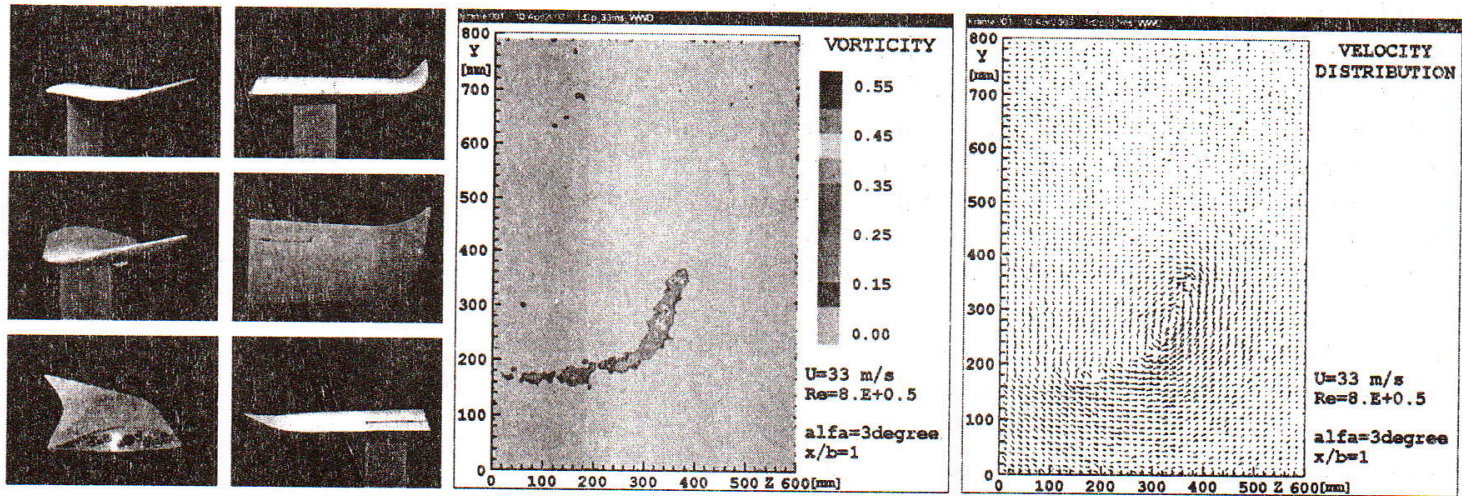

Fig. 13: Wing tip model D

\section{Conclusion}

Experimental instrumentation for investigating of the flow field behind a winglet model has been designed, manufactured and setup. A newly designed traverse mechanism has made it possible for measurements to be made at high spatial resolution within a large enough area for full size wing tip models to be tested. Results have been presented to demonstrate this capability. An additional feature of the system is that the time required for testing is relatively short.

\section{Acknowledgement}

The authors wish to acknowledge the support of the academic and technical staff of the University of Glasgow, Aerospace Engineering Department. Special thanks go to the technical staff from the Spencer Street Laboratory, especially, to Mr. R. Gilmour, who helped with the experimental set-up, and to Mr. T. Smedley, Mr. A. Erwin, Mr. J. Kitching and Mr. A. Fraser for their help in manufacturing and installing the equipment.

Thanks also go to Mr. Potmesil and to Hph. for manufacturing the winglet models.

$\mathrm{Mr}$ P. Anderle was supported by a studentship provided by BAE Systems.

\section{References}

[1] Lanchester, F. W.: Aerodynamics. London: Constable \& Co, 1907.

[2] Prandtl, L.: Theory of Liffing Surfaces. NACA TN9, 1920.

[3] Whitcomb, R. T.: A Design Approach and Selected Wind-Tunnel Result at High Subsonic Speed for Wing-Tip Mounted Winglets. NASA TN D-8260, July 1976.

[4] Montoya, L. C., Jacobs, P. F., Flechner, S. G.: Effect of Winglets on a First-Generation Jet Transport Wing, III-Pressure and Spanwise Load Distributions for a Semispan Model at Mach 0.3. NASA TN D-8478, June 1977.

[5] Marsden, D. J.: Winglets for Sailplanes. Technical Soaring, Vol. 15, No. 4, October 1991.

[6] Thorsen, O. R.: Theoretical and Experimental Analysis of the Winglets Designed for the High-Performance Sailplane $A S W-27$. Thesis, TU Delft, March 1999.

[7] Nicks, O. W.: Wing Extension for Improving Climb Performance. AIAA-83-2556, October 1983.

[8] Nics, O. W.: A Physical View of Wing Aerodynamics. Technical Soaring, Vol. 17, No. 4, October 1993.

[9] Kiceniuk, T.: Dynamic Soaring and Sailplane Energetic. Free flight-vol libre, Dec/Jan 2001.

[10] Smith, S.: Do Winglets Work. Free flight-vol libre, Aug/Sep 1997. 
[11] Masak, P.: Winglet Design for Sailplanes. Free flight-vol libre, April/May 1992.

[12] Crosby, C. P., Ashman, P., Terblanche, H.: Full-Scale In-Flight Pressure Measurements on a Winglet Fitted to an AS-W 20. Technical Soaring, Vol. 20, No. 3, July 1996.

Ing. Pavel Anderle e-mail: anderle@aerospace.fsik.cvut.cz

Aerospace Engineering Department

Czech Technical University in Prague

Karlovo nám. 13

12135 Prague 2, Czech Republic

Dr. Ladislav Smrček

e-mail: ladislav@aero.gla.ac.uk

Dr. Frank N. Coton

e-mail: frank@aero.gla.ac.uk

Aerospace Engineering Department

James Watt Building

University of Glasgow

Glasgow G12 8QQ

Scotland, United Kingdom 